Business and Economics Research Journal

Volume 9 Number 12018

pp. $123-136$

ISSN: $1309-2448$

DOI Number: 10.20409/berj.2018.96

\title{
Bireysel Yenilikçi Davranışların Çalışma Arkadaşları ile Çatışma ve İşten Ayrılma Niyeti Üzerine Etkileri: Kamu Sektöründe Bir Araştırma
}

\author{
Adnan Eroğlu ${ }^{\mathrm{a}}$
}

\author{
Mustafa Kemal Topçu ${ }^{\mathrm{b}}$
}

\author{
H. Nejat Basım ${ }^{\mathrm{c}}$
}

Öz: Bireylerin yenilikçi davranış sergilemelerinin altında yatan bilişsel ve motivasyonel süreçlerde bireysel ve bağlamsal faktörlerin rolünü anlamamıza önemli katkı sağlayan literatürde, yenilikçi davranışın bireysel çıktılarına yönelik çalışmalara çok az rastlanmaktadır. Çalışanların yenilikçi davranış sergilemesinin kurumsal menfaat açısından rolü ele alınırken, bireysel olarak karşılaşılabilecek olumsuz durumlar ya da karanlık yönü genellikle göz ardı edilmektedir. Bu kapsamda, çalışanların yenilikçi davranış sergilemelerinin çalışma arkadaşları ile çatışma ve işten ayrılma niyeti üzerindeki etkilerini incelemek üzere karma yöntem kullanılarak iki aşamalı bir çalışma yapılmıştır. Birinci aşamada savunma sanayinde faaliyet gösteren bir kamu kuruluşunda 186 çalışanın katılım sağladığı bir anket uygulanmıştır. Araştırmada, çalışanların yenilikçi davranışlarının çalışma arkadaşları ile çatışma ve işten ayrılma niyetleri üzerinde anlamlı bir etkiye rastlanmamıştır. Bunun nedenlerinin araştırılması için ikinci aşama olarak nitel bir araştırma yöntemi olan odak grup çalışması yapılmıştır.

Anahtar Sözcükler: Yenilikçi Davranış, Çalışma Arkadaşları İle Çatışma, İşten Ayrılma Niyeti, Odak Grup Yöntemi, Karma Yöntem

JEL Sınıflandırması: M12, M14

\section{Effects of Individual Innovative Behaviors on Conflict with Co-Workers and the Intent-to-leave: A Research in the Public Sector}

\begin{abstract}
There is a scant literature on personal outcomes of innovative work behaviors, whereby it motivates us to understand the role of individual and organizational factors in cognitive and motivational processes underlying individual innovative behaviors. While the role of innovative work behaviors is studied as a gain for organizations, negative contingencies or dark side are neglected. To this end, a two-step study consisting of mixed methodology is conducted to identify effects of innovative work behaviors on conflict with co-workers and intent-to-leave. At first step, a survey, in which 186 employees participated, was employed in a public institution operating in defense industry. The study indicates that there is no significant effect of innovative work behaviorson conflict with co-workers, and intent-toleave. In order to determine the motivators, a focus group study as a qualitative research method was performed.
\end{abstract}

Keywords: Innovative Behavior, Conflict With Co-Workers, Intent-To-Leave, Focus Group Method, Mixed Method

JEL Classification: M12, M14

aPhD. Candidate, Cyprus Turkish Peace Forces Command, Cyprus, aeroglu1996@gmail.com (ORCHID ID: 0000-0003-0952-9114) bPhD., ST Strategy and Technology Development LLD, Ankara, Turkiye, topcumustafakemal@gmail.com (ORCID ID: 0000-0002-32981283)

cProf., PhD., Baskent University, Faculty of Economics and Andministrative Sciences, Ankara, Turkiye, nbasim@baskent.edu.tr (ORCID ID: 0000-0002-3407-5049) 


\section{Giriş}

Rekabet avantajının elde edilmesinde yeniliklerin sürekli takip edilmesi ve bu yeniliklerin başarılı bir şekilde uygulanması, günümüz örgütlerinin sahip olmaya çalıştğı bir yetenek olarak her geçen gün önemini artırmaktadır. Örgütlerin daha fazla yenilikçi olabilmesi için bir seçenek, çalışanların yenilikçi davranış sergileme konusunda cesaretlendirilmesidir. Nitekim yeniliğin temeli fikirler ve bu fikirleri geliştiren, uygulayan ve üzerinde değişiklikler yapan bireyin kendisidir (Scott ve Bruce, 1994: 580). Dinamik iş ortamında, örgütlerin uzun dönem hayatta kalmaları ve sürdürülebilir rekabet avantajı sağlamak için çalışanların yenilikçi davranışlar sergilemesi gerektiği görüşü birçok araştırmacı tarafindan kabul görmektedir (Ancona ve Caldwell, 1987: 1; Scott ve Bruce, 1994: 580; Oldham ve Cummings, 1996: 607; Janssen vd., 2004: 129; Shih ve Susanto, 2011: 111; Yuan ve Woodman, 2010: 323; Montani vd., 2012: 46; Topcu vd., 2015: 67).

Yeni durumlara, beklenmedik koşullara uyum sağlamak ve bu uyumu kolaylaştırıcı bir performans sergileyebilmek için çalışanların yenilikçi uygulamalarına her zaman ihtiyaç vardır. Yenilikçi davranışın altında yatan bilişsel ve motivasyonel süreçlerde bireysel ve bağlamsal faktörlerin rolünü anlamamıza önemli katkı sağlayan literatürde, sıklıkla yenilikçi davranışın belirleyicilerine ağırlık verilmiş, yenilikçi davranışın bireysel çıktlarına ise çok az değinilmiştir (Janssen vd., 2004: 129). Yenilikçi bireysel davranışların örgütsel etkililiğe katkı sağladığı büyük ölçüde iddia edilirken (Van de Ven, 1986: 590; Ancona ve Caldwell, 1987: 1; Woodman vd., 1993: 293; Oldham ve Cummings, 1996: 607), bir çalışanın yenilikçi yaklaşım sergilemesi için ödemek zorunda olduğu bedel, başka bir ifade ile yenilikçi davranışın negatif yönü göz ardı edilmektedir (Janssen, 2003: 347; Janssen vd., 2004: 130; Shih ve Susanto, 2011: 111).

Literatürde yer alan bu sorunsaldan yola çıkılarak, bireylerin yenilikçi davranışlarının sonucunda karşılaşabilecekleri olumsuzluklardan çalışma arkadaşları ile çatışma ve işten ayrılma niyeti arasındaki ilişkileri araştrrmak maksadıyla bu çalışma tasarlanmıştır. Ankara'da savunma sanayinde faaliyet gösteren bir kamu kuruluşundaki çalışanlara anket uygulayarak çalışanların yenilikçi davranış sergileme düzeyleri ölçülmüş, değişkenler arasındaki doğrudan ve dolaylı etkiler araştrıımıştır. Araştırmanın nicel kısmında elde edilen bulguların tartışılması ve literatür ile örtüşmeyen sonuçların nedenlerinin tespit edilmesi maksadıyla nitel yöntem olarak odak grup çalışması yapılmıştır. Karma yöntemle yapılan bu çalışma hem yenilikçi davranışın olumsuz yönünü araştırması bakımından hem de nicel ve nitel yöntemin bir arada kullanılması bakımından önemlidir. Bu çerçevede çalışmanın geri kalan kısmında öncelikle literatür tartışılarak hipotezler üretilmektedir. Nicel araştırmanın bulguları tartışıldıktan sonra nitel araştırma bulgularına yer verilmektedir. Sonuç olarak elde edilen bulgular doğrultusunda akademisyen, uygulamacı ve uzmanlar için ipucu niteliği taşıyacak bazı tavsiyelerde bulunulmaktadır.

\section{Kuramsal Çerçeve}

\subsection{Yenilikçi Davranış}

Bireyin yenilikçi davranışı işyerinde yeni ve pratik fikirlerin maksatıı oluşumu ve uygulamaya konması olarak tanımlanmaktadır (Montani vd., 2012: 43). Bireysel yenilikçi davranışı çalışanların yeni ürünler, yeni teknikler ile yeni üretim süreçlerini uygulamaya koyması ile başlayan baştan sona davranışsal bir süreç olarak tanımlanmak da mümkündür (Yu vd., 2013: 146). Bir başka bakış açısı ile çalışanların çok çaba gerektiren ve stresli olaylara dayanırken sergilemeleri beklenen farklı ve sonuç odaklı yaklaşımlarla etkili başarma gayretidir (Janssen, 2000: 288). Her durumda belirli olan örgütsel amaca uygun yenilik yaratan her birey, sürdürülebilir rekabet avantajı sağlayan inovasyonun kendisi kadar değerlidir (Topcu vd., 2015: 69). Yenilikçi davranışa örnek olarak; çalışanlar tarafindan örgütsel amaçlara ulaşmayı sağlayacak yeni yolları önerme, yeni teknolojileri keşfetme, yeni çalışma yöntemleri uygulama ve yeni kaynakları araştırma ifade edilebilir (Yuan ve Woodman, 2010: 324).

Örgütlerin çevresi çok değişken bir yapıdadır. Bazen örgütler tarafindan uygulanan rutinler hızlı değişime cevap veremeyebilir. Bu yüzden çalışanların yeni yaklaşımlar, teknikler veya prosedürler geliştirmesi ve uygulaması gerekebilir (Shih ve Susanto, 2011: 113). Çalışanları yenilikçi davranmaya iten nedenler arasında; örgütlerde meydana gelen değişimlerin çalışanlara olan yansımaları, örgüt içinde daha fazla 
bağımsızlık elde etme ve örgütsel ödüllere ulaşabilme ile değişime uyum sağlamak için örgüt içindeki kronikleşmiş sorunlara çözümler üretme sayılabilir (Basım vd., 2008: 123).

Yenilikçi davranış sergilemek; performans gelişimi, iş tatmini, yaşam tatmini, stresi azaltma, daha iyi kişiler arası ilişkiler ve kişisel gelişim gibi faydalar sağlayabilmektedir (Janssen vd., 2004: 130). Ancak yenilikçi davranışın sadece pozitif yönlerini vurgulamak, yanıltıcı sonuçlara yönlendirerek yenilikçi davranışın karanlık yönünün ihmali sonucunu doğurabilir (Shih ve Susanto, 2011: 113). Yenilik, fikir sahibi bireylerin örgüt içindeki statülerini ve ödüllerini risk altında bırakabilir (Kanter, 1988: 170; Janssen vd., 2004: 130). Bir çalışanın değişime dönük yenilikçi fikirleri, yerleşik iş ilişkileri, grup normları veya iş arkadaşlarının bir başkası hakkındaki beklentilerini zorlayıcı olabilir.

\section{2. Çalışma Arkadaşları ile Çatışma}

Çatışma, taraflardan birinin çıkarlarına diğer tarafin karşı çıkması veya olumsuz etkilemesi olarak algılaması süreci şeklinde tanımlanmaktadır (Wall ve Callister, 1995: 517). Basım vd. (2009: 21) da çatışmaya bir süreç olarak yaklaşmakta ve çatışmayı kişilerin arasındaki uyuşmazlık ve ahenksizlik olarak nitelendirmektedir. Bu tanımlardan hareketle çatışmanın, çalışanların çıkarlarının bir grup, şirket veya topluluk içindeki diğer çalışanların çıkarları ile örtüşmemesi durumunda ortaya çıkabileceği ifade edilebilir (Shih ve Susanto, 2011: 114). Hatta davranışsal boyutta kişilerin kendi çıkarlarını ön plana çıkarmak maksadıyla diğerlerinin ihtiyaçlarının karşılanmasına engel olduğu bir süreçtir (Basım vd., 2009: 21).

İşyerindeki çatışmaların çıkma sebebi çalışanların işle ilgili yaklaşımları, fikirleri ve düşüncelerindeki farklılıklar olabildiği gibi kişiler arasındaki uyumsuzluklar da olabilir. Nitekim, çalışma arkadaşları ile çatş̧malar olumsuz duygulardan, düşmanlıklardan, karşııkı engellemelerden, uyumsuzluklardan, gerginliklerden, değer uyuşmamasından, örgütsel ve yönetsel süreçlerden kaynaklanabilmektedir (Basım vd., 2009: 21). Diğer taraftan, çalışma arkadaşları birbirlerine işleri ile ilgili yardımda bulunabildikleri gibi bilgi akışı sağlayabilmekte ve psikolojik destek verebilmektedir (Chiaburu ve Harrison, 2008: 1084). Yine de akranlar arasındaki ilişki tamamen mübadele ilişkisidir (Gouldner, 1960: 169).

Spector ve Bruk-Lee (2008) tarafindan belirtildiği gibi işyerindeki çatışmalar stres yaratan önemli faktörlerin başında gelmektedir. Duygu merkezli iş stresi modeline göre, çatş̧malar stres faktörü olarak çalışanların negatif duygusallıklarını artırmakta ve davranışsal, fiziksel ve psikolojik rahatsızlıklara neden olmaktadır (Spector, 1998). Frone (2000) da kişiler arası çatş̧maların bireylerin ümitsizlik ve değersizlik duygularına kapıldığını raporlamaktadır. Sonuç olarak kişiler arası çatışmaların işyeri huzurunu bozan temel etmenlerden birisi olduğu ifade edilebilir. Ayrıca, çatışmaların ve çözümlerinin işe ayrılan süreden ve emekten kayıplara yol açţğı da değerlendirilmesi gereken bir husustur (Schwartz ve Stone, 1993). Çatışmaların çözümü için harcanan kaynak bilişsel ve duygusal kaynakların da tükenmesine neden olmaktadır (Hobfoll, 1998).

\section{3. İşten Ayrılma Niyeti}

İşten ayrılma niyeti, örgütten ayrılmak için bilinçli ve önceden düşünülmüş niyeti ifade etmektedir (Tett ve Meyer, 1993: 262). İşten ayrılma niyeti, bireylerin yakın gelecekte belirli bir zamanda örgütten sürekli olarak ayrılma eğiliminde olma olasılı̆̆ı şeklinde de tanımlanmaktadır (Vandenberg ve Nelson, 1999: 1315). Bu tanımlar ışığında işten ayrııma niyetini, çalışanın mevcut örgütten gelecekte ayrılmaya ilişkin bilinçli karar verme isteği olarak tanımlamak mümkündür. Arnold ve Feldman (1982) işten ayrılma niyetini işten ayrılmanın temel belirleyicisi olduğunu, alternatif imkânların varlığının bu süreçte düzenleyici rolü olduğunu belirtmiştir. Zira işten ayrılma niyeti işten ayrılmanın temel göstergesi olarak kabul edilmektedir (Cohen, Blake ve Goodman, 2015). İşten ayrılma niyetinin işten ayrılmaya dönüşmesi ortalama alt ay kadar sürmektedir (Tett ve Meyer, 1993).

Bireysel özellikler, kıdem, pozisyon bağlılığı ve iş güvencesi gibi sebepler çalışanları alternatif arayışına itebilmektedir (Arnold ve Feldman, 1982). Çalışanın işten ayrılma niyetinde olması kişisel faktörlerden kaynaklanabileceği gibi örgütsel ve yönetsel faktörlerden de etkilenebilmektedir. İşten ayrılma niyetleri nedenleri arasında huzur olmayan çalışma ortamları, kariyer ilerlemesinin yokluğu ve daha cazip ekonomik imkanlar yer almaktadır (Jam vd., 2012). Bununla birlikte, emeklilik, ölüm ve hastalık gibi nedenlerden de 
işten ayrılmalar olmaktadır. Madalyonun diğer yüzünde ise örgütte kalma niyeti bulunmaktadır. İ̧ine çok fazla enerji harcayan ya da işiyle bütünleşen, özdeşleşen bir çalışan için işten ayrılma niyeti çok uzaktır (Halbesleben ve Wheeler, 2008: 246). Çalışanlar işyerinin sağladığı esneklik, kariyer gelişimi, yenilikçi fikirleri teşvik gibi imkanlardan dolayı da örgütte kalmaya devam edebilir (De Lange vd., 2008).

Abbasi ve Hollman (2000) işten ayrılmanın, hem kamuda hem de özel sektörde azalan verimliliğin ve düşen moralin en önemli nedenlerinden biri olduğunu ileri sürmektedir. Çalışanların örgütte kalma konusundaki isteksizliği, beklentilerinin büyük ölçüde karşılanmamış olmasıyla açıklanmaktadır (Porter ve Steers, 1973). İşin gözlenebilen yönlerine ilişkin karşılanmamış beklentiler ve hayal kırıklıkları, işi bırakma kararında önemli bir etkiye sahiptir (Van de Ven, 2003). İşten ayrılmanın önlenmesi için çalışanların ihtiyaçlarının karşılandığından emin olunması önemlidir (Mafini ve Dubihlela, 2013: 529).

Çalışanın işten ayrııması; hem işe alım, yerleştirme ve seçim, geçici personel ve yönetim zamanı gibi doğrudan maliyetleri hem de daha önemli olan moral, kalan çalışanlar üzerindeki baskı, öğrenme maliyetleri, ürün/hizmet kalitesi, örgütsel bellek gibi dolaylı maliyetler ile sosyal sermayenin kaybını artırabilir (Dess ve Shaw, 2001).

\subsection{Değişkenler arası ilişskiler ve Araştırmanın Hipotezleri}

Yeni fikirlerin diğer çalışanlara negatif sinyaller göndermesi ile yenilikçi fikirler diğer çalışanları belirsizlik ve güvensizlik ikilemi ile yüz yüze bırakabilmektedir. Öyle ki, bir çalışanın çalışma arkadaşı tarafindan engellenmesi veya kızdırılması, yenilikçi uygulamaların iş ilişkilerine, grup normlarına ve iş arkadaşlarının bir başkası hakkındaki beklentilerine meydan okuması çalışma arkadaşları arasında çatışma yaşanmasına sebep olabilmektedir (Jones, 2001: 398; Janssen, 2003: 349). Çalışanların yenilikçi düşünceleri, var olan koşullar ile uyum içindeki çalışanlar için güvensizlik, belirsizlik ve stres getirebileceği için çalışma arkadaşları ile arasında çatışmaya neden olabilmektedir (Shih ve Susanto, 2011: 112; Janssen, 2003: 347; Janssen vd., 2004: 130). Nitekim Janssen (2003: 347), yenilikçi çalışanların değişimi önlemek isteyen ve değişime direnç gösteren çalışma arkadaşları ile çatışma yaşama riskine vurgu yapmaktadır.

"Değişime direnç" paradigması dâhilinde, çalışma arkadaşlarının, değişimin etrafindaki stres, belirsizlik ve güvensizlikten kaçınma arzuları, alışkanlıkları ve aşina oldukları uygulama öncelikleri, bilişsel uyumsuzluğu azaltma istekleri ve mevcut nazariye ile uygulamalara bağlılıkları yüzünden değişime dönük yenilikçi fikirleri engelleyici tutum içerisinde olabilecekleri ifade edilebilir (Janssen, 2003: 349). İnsanların sahip olduğu alışkanlıkları ve aşina oldukları uygulamalara dönük öncelikleri kırmak güçtür, çünkü insanlar benliğinde mevcut özgün davranışlara dönmeye meyilli ve değişimi önlemeye eğilimlidir (Jones, 2001: 398; Janssen, 2003: 349). Söz konusu değişime direnç, değişim için fikirler ileri süren yenilikçi çalışanın bu değişimi önleyen çalışma arkadaşları tarafindan engellenmesi veya öfkelendirilmesi suretiyle kişiler arası çatışmaya dönüşebilmektedir.

Çalışma arkadaşlarından kaynaklanan işyerindeki sosyal çevre; bilgi gizleme, işe geç gelme, kaytarma ve işten ayrılma niyeti gibi bir kııım geri çekilme davranışlarına neden olabilmektedir (Mathieu ve Kohler, 1990; Kidwell ve Bennett, 1993; Harrison, 2002). İşyerinde çatışma yaşayan çalışanların iyilik halinin zayıfladığı da tespit edilmiştir (Sonnentag vd., 2013). Nitekim Spector ve Bruk-Lee (2008) çatı̧̧malar çalışanların performansını azaltmakla kalmamakta sağılıklarını ve iyilik halini de olumsuz etkilemektedir. Çalışanların şikayetleri gerilim tipi ağrılara, depresyona, tükenmişliğe ve psikosomatik rahatsızlıklara yoğunlaşmaktadır (Frone, 2000; De Dreu vd., 2004). Bu şekilde, çalışanların üstleri ve akranları ile çatı̧̧ma yaşamaları işten ayrılma niyetini artıran olumsuz bir etkendir (Mimaroğlu, 2008). Nitekim kişiler arası çatışmaların yoğun olduğu işyerlerinde işten ayrılma niyetinin de artması kaçınılmaz bir durum olarak nitelendirilmektedir (Spector ve Bruk-Lee, 2008: 280). Zira Chen ve Spector (1992), Rainey (1995), Spector ve Jex (1998) kişiler arası çatışma ile işten ayrılma niyeti arasında pozitif bir ilişki olduğunu tespit etmiştir.

Çalışma arkadaşları ile çatışma yaşanmasının yanı sıra, yenilikçi davranışın işten ayrılma niyetini olumlu yönde etkilediği belirtilmektedir (Shih ve Susanto, 2011: 122). Yenilikçi davranış sergileyen çalışanlar çalışma arkadaşlarına kıyasla daha çok performans gösterebileceği (Janssen vd., 2004: 132) için diğer örgütlerde iş bulma konusunda daha fazla firsata sahip olabilmektedir (Shih ve Susanto, 2011: 112). Nitekim, 
yüksek performanslı çalışanlar daha fazla iş arayışı davranışı göstermekte, bu da söz konusu çalışanların işten ayrılacağına dair büyük bir olasılık yaratmaktadır (Martin vd., 1981: 116; Shih ve Susanto, 2011: 112). Bu kapsamda yapılandırılan araştırma modeli Şekil 1'de sunulmuştur.

Şekil 1. Araştırma Modeli

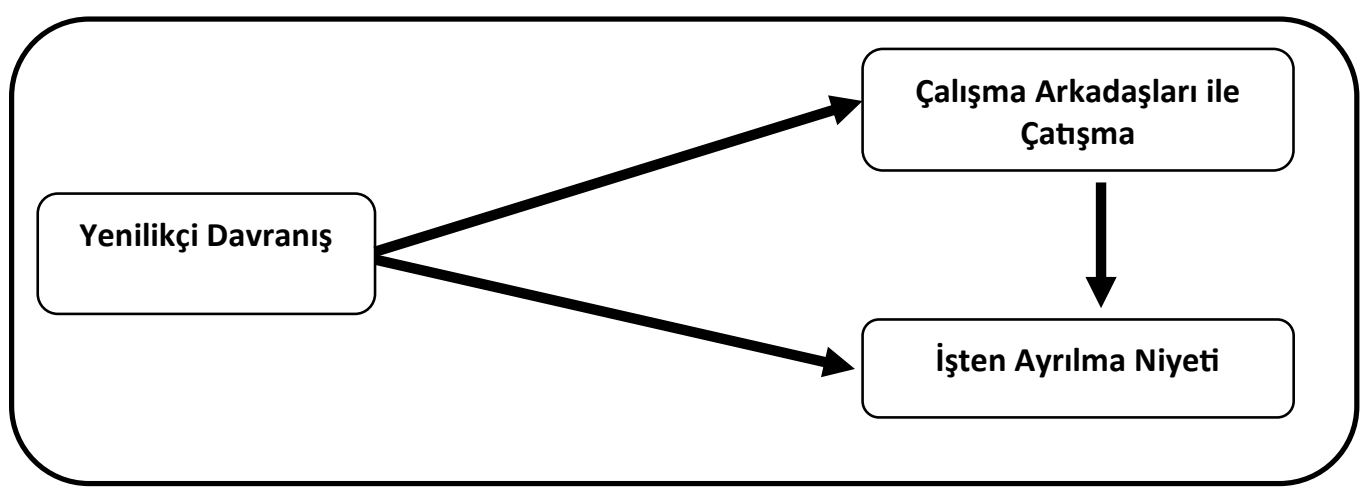
edilecektir:

Çalışmada, yukarıda anlatılan kuramsal gerçekliği sınamak üzere aşağıda belirtilen üç hipotez test

Hipotez 1 (H1): Bireysel yenilikçi davranışlar çalışma arkadaşları ile çatışma düzeyini anlamlı etkilemektedir.

Hipotez 2 (H2): Bireysel yenilikçi davranışlar işten ayrılma niyetini anlamlı etkilemektedir.

Hipotez 3 (H3): Bireylerin çalışma arkadaşları ile çatışma düzeyleri işten ayrıma niyetlerini anlamlı etkilemektedir.

\section{Araştırma Yöntemi}

\subsection{Nicel Araştırma}

\subsubsection{Katılımcılar}

Araşttrmanın ana kütlesini, Ankara genelinde savunma sanayinde faaliyet gösteren bir kamu kuruluşunda çalışan 552 personel oluşturmaktadır. Araştırmanın örneklemini ise, bu çalışanlar arasından basit tesadüfï örneklem yöntemi ile seçilen bireyler oluşturmaktadır. Güven aralığı \%5, anlamlılık seviyesi \%5 alınarak yapılan hesaplama sonucunda 227 personelin yeterli olacağı tespit edilmiştir. Bu çerçevede basit tesadüfî örneklem yöntemi ile tespit edilen 250 personelden gönüllülük esasında anketleri doldurmaları istenmiştir. Anketleri doldurarak teslim eden personel sayısı 205 olurken, tam doldurulmayan anketlerin analiz dışı tutulması sonucunda örneklem 186 çalışan tarafindan oldurulan anketlerden oluşmuştur. Ankete katılan çalışanların yaşlarının ortalaması $32,35(s s=6,69)$ ve mevcut kurumda çalışma sürelerinin ortalaması 7,70 yıl (ss=5,92)dir. Diğer demografik değişkenler Tablo 1'de yer almaktadır. Çalışanlar ağırlıklı olarak erkek, lisans eğitim seviyesine sahip bir profil sergilemektedir.

Tablo 1. Betimleyici İstatistik

\begin{tabular}{|c|c|c|c|c|c|c|c|}
\hline \multicolumn{2}{|r|}{ Faktör } & \multirow{2}{*}{$\begin{array}{c}\text { Frekans } \\
125\end{array}$} & \multirow{2}{*}{$\begin{array}{c}\text { Yüzde } \\
67,3\end{array}$} & \multicolumn{2}{|r|}{ Faktör } & \multirow{2}{*}{$\begin{array}{c}\text { Frekans } \\
5\end{array}$} & \multirow{2}{*}{$\begin{array}{c}\text { Yüzde } \\
2,7\end{array}$} \\
\hline \multirow{4}{*}{ Statü } & İşgören & & & \multirow{4}{*}{$\begin{array}{l}\text { Eğitim } \\
\text { Durumu }\end{array}$} & $\begin{array}{l}\text { Önlisans veya } \\
\text { daha az }\end{array}$ & & \\
\hline & Alt Kademe Yönetici & 23 & 12,4 & & Lisans & 125 & 67,3 \\
\hline & Orta Kademe Yönetici & 28 & 15,0 & & Y.Lisans & 53 & 28,3 \\
\hline & Üst Kademe Yönetici & 10 & 5,3 & & Doktora & 3 & 1,8 \\
\hline \multirow{3}{*}{ Cinsiyet } & Erkek & 101 & 54 & & Ortalama & S.S. & \\
\hline & Kadın & 85 & 46 & Yaş & 32,35 & 6,69 & \\
\hline & & & & Tecrübe & 7,70 & 5,92 & \\
\hline
\end{tabular}




\subsubsection{Araştırmanın Ölçekleri}

Bireysel Yenilikçi Davranış Ölçeği Katılımcıların yenilikçi davranış düzeyleri, Janssen (2003) tarafindan geliştirilen ve dokuz ifadeden oluşan "Bireysel Yenilikçi Davranış" ölçeğinin Türkçeye uyarlanması ile ölçümlenmiştir. Janssen (2003) tarafindan yapılan çalışmada yenilikçi davranışlar; fikir üretme (üç ifade), fikir geliştirme (üç ifade) ve fikir gerçekleştirme (üç ifade) şeklindedir. Dokuz ifadeden oluşan ölçekte ifadeler, "Zor durumlar için yeni fikirler üretirim (fikir üretme)", "Yenilikçi fikirlere uygulamaya dönük destek sağlarım (fikir geliştirme)", "Yenilikçi fikirleri kullanılabilir ürünlere dönüştürürüm (fikir gerçekleştirme)" şeklindedir. Ölçekte cevaplar 7'li likert ölçeği ile alınmıştır (1=Kesinlikle katılmıyorum, 7=Kesinlikle katılıyorum). Ölçeğin Cronbach Alfa güvenirlik değeri 0.97 olarak hesaplanmıştır.

Çalışma Arkadaşları ile Çatışma ölçeği Katılımcıların çalışma arkadaşları ile yaşadığı çatışma düzeyleri, Janssen (2003)'in dört ifadeden oluşan ölçeğinin Türkçeye uyarlanması ile ölçümlenmiştir. Anılan ölçeğe ait dört ifade; "Sen ve çalışma arkadaşların işyeri ile ilgili hususlarda anlaşmazlık yaşar mısın?", "Sen ve çalışma arkadaşların işyeri meselelerinde farklı düşünceye mi sahipsin?", "Sen ve çalışma arkadaşların arasındaki kişisel ilişkilerde gerilimler yaşar mısın?" ve "Sen ve çalışma arkadaşların işinle alakalı konularda farklı bakış açılarına sahip misin?" şeklindedir. Ölçekte cevaplar 7'li likert ölçeği ile alınmıştır (1=Kesinlikle katılmıyorum, 7=Kesinlikle katılıyorum). Ölçeğin Cronbach Alfa güvenirlik değeri 0.86 olarak hesaplanmıştır.

İşten Ayrılma Niyeti Ölçeği İşten ayrılma niyetini ölçmek üzere, Tak ve Çiftçioğlu (2009) tarafindan oluşturulan, beş ifadelik "Örgütte Kalma Niyeti Ölçeği” kullanılmıştır. Ölçek 5'li Likert tarzında (1=Kesinlikle Katılmıyorum, 5=Tamamen Katılıyorum) hazırlanmış ve 2 ifade (1 ve 3'üncü ifadeler) ters kodlanmıştır. Ölçekteki ifadeler, "Bu işyerinde önümüzdeki yıllarda da çalışmak isterim”, "Önümüzdeki yıllarda başka bir işyerinde çalışmayı düşünüyorum", "Önümüzdeki 5 yı içinde bu işyerinden ayrılmayı istemiyorum", "Diğer işyerlerinde iş bulma olanağım olup-olmadığına bakıyorum", "Sık sık işten ayrılmayı düşünüyorum" şeklindedir. Polat ve Meydan (2010) tarafindan kullanılan ölçekte, Cronbach Alfa güvenirlik değeri 0.91 olarak tespit edilmiştir.

\subsection{3. Ölçeklerin Geçerliği}

Kullanılan ölçeklerin geçerliliğini test etmek için doğrulayıcı faktör analizi yapılmıştır. Bu çerçevede ölçeklerin birincil düzey yapıları test edilmiş ve sonuçları Tablo 2'de gösterilmiştir. Marsh ve arkadaşları (1988), Bentler (1990) ve Kline (2004) RMSEA uyum endeks değerinin kabul edilebilir sınırını 0,08 olarak ifade etmektedir. Diğer yandan yapısal eşitlik modelinde kullanılacak indeksler ve değerleri konusunda tartşsmalar halen devam etmektedir. Tablo incelendiğinde uyum indekslerinden RMSEA hariç diğerlerinin kabul edilebilir sınırlar içerisinde olduğu, RMSEA değerinin ise 0,081 olduğu görülmektedir. Diğer uyum indeks değerlerinin sınırlar içerisinde olması onbindebirlik bir sapma ile bu sınır değerin kabul edilebileceğini düşündürmektedir. Zira Tabachnick ve Fidell (2001:700) örneklem sayısının küçük olduğu gruplarda RMSEA değerinin beklenen değerden yüksek çıkabildiğini belirtmektedir. Ayrıca Hu ve Bentler (1999) da farklı örneklem büyüklükleri üzerinde yapmış oldukları araştırma sonucunda örneklemin 250'den az olması halinde RMSEA'nın kabul edilebilir limitin üzerinde değer aldığını belirlemişlerdir. Bu sebeple analize devam edilmiş ve Tablo 2 'de yer alan doğrulayıcı faktör analizi bulgularından anlaşılacağı üzere, ölçeklerin test edilen yapıları doğrulanmıştır.

Tablo 2. Ölçeklerin Doğrulayıcı Faktör Analizi Sonuçları

\begin{tabular}{|l|l|l|l|l|l|l|l|}
\hline Ölçek & $\mathbf{\Delta \mathbf { x } ^ { 2 }}$ & $\mathbf{d f}$ & $\mathbf{\Delta \mathbf { \chi } ^ { 2 }} \mathbf{d d f}$ & $\mathbf{R M R}$ & $\mathbf{G F I}$ & RMSEA & CFI \\
\hline Bireysel Yenilikçi Davranış & 41,501 & $\mathbf{2 4}$ & 1,729 &, 069 &, 925 &, 081 &, 974 \\
\hline Çalışma Arkadaşları ile Çatışma & 0,008 & 1 & 0,008 &, 002 & 1,000 &, 000 & 1,000 \\
\hline İşten Ayrılma Niyeti & 6,222 & 5 & 1,244 &, 042 &, 978 &, 047 &, 994 \\
\hline
\end{tabular}

Not: RMSEA= Root Mean Square Error of Approximation; GFI= Goodness of Fit Index, CFI= Comparative Fit Index; RMR= Root Mean Square Residual. $(p<.001)$. 


\subsubsection{Bulgular}

Değişkenler arası korelasyon analizi yapılabilmesi için yapısal geçerliği doğrulanan ve güvenirlik derecesi oldukça yüksek bulunan ölçeklerin madde puanları toplanmış ve madde ortalama puanları hesaplanmıştı. Ölçeklerin ortalama değerleri, standart sapmaları, güvenirlik katsayısı olarak Cronbach Alfa değerleri ve değişkenler arası korelasyonlara Tablo 3'te yer verilmiştir. Tablodan da görüldüğü üzere bireysel yenilikçi davranışların ortalaması 7'li likert ölçeğine göre ortalamanın üzerindedir (ort.=4,96). Çalışma arkadaşları ile çatı̧̧ma ortalaması ise neredeyse tam orta noktadadır (ort.=3.43). işten ayrılma niyeti ise $5^{\prime}$ li likert ölçeğine göre ortalamaya çok yakındır (ort=2,63).

Tablo 3. Değişkenlere Ait Güvenirlik Değerleri ve Korelasyonlar

\begin{tabular}{|l|c|c|c|c|c|c|}
\hline Faktör & Ort. & SS & C.A. & $\mathbf{1}$ & $\mathbf{2}$ & $\mathbf{3}$ \\
\hline (1) Bireysel Yenilikçi Davranış & 4,96 & 1,10 & .926 & 1 & & \\
\hline (2) Çalışma Arkadaşları ile Çatışma & 3,43 &, 92 & .832 & .116 & 1 & \\
\hline (3) İşten Ayrıma Niyeti & 2,63 & 1,06 & .830 & -.093 & .39 & 1 \\
\hline
\end{tabular}

Ort.= Ortalama, SS= Standart Sapma, C.A.= Cronbach alfa güvenirlik katsayısı. * $p<.01$ (Tek yönlü).

Elde edilen bulgular, bireysel yenilikçi davranış algılamalarının, çalışma arkadaşları ile çatışma düzeyleri ( $r=0.116, p>.01)$ ve işten ayrılma eğilimleri $(r=-0.09, p>.01)$ arasında anlamlı bir ilişki olmadığını göstermektedir. Benzer şekilde çalışma arkadaşları ile çatışma ve işten ayrılma niyeti arasında da anlamlı bir ilişki olmadığı görülmektedir ( $r=0.39, p>.01)$. Değişkenler arasında herhangi bir ilişki olmadığı korelasyon analizi sonucunda ortaya çıkmakla birlikte regresyon analizi yöntemi ile bu sonuç doğrulanmıştır. Bu amaçla, değişkenler arasındaki doğrudan etkileri görmek üzere basit doğrusal regresyon analizi yapılımıştr. Regresyon analizi sonuçları Tablo 4'te yer almaktadır.

Tablo 4. Regresyon Analizi

\begin{tabular}{|l|l|l|l|}
\hline & Regresyon Modeli & $\mathbf{F}$ & $\mathbf{p}$ \\
\hline 1 & Bireysel Yenilikçi Davranış-> Çalışma Arkadaşları ile Çatışma & 1,447 & 0,231 \\
\hline 2 & Bireysel Yenilikçi Davranış -> İşten Ayrılma Niyeti & 0,977 & 0,325 \\
\hline 3 & Çalışma Arkadaşları ile Çatışma-> İşten Ayrılma Niyeti & 0,168 &, 683 \\
\hline
\end{tabular}

Bireysel yenilikçi davranış ile işten ayrılma niyeti arasındaki etkileşimin araştrııması maksadıyla oluşturulan regresyon modelinin istatistiksel olarak anlamlı olmadığı bulgulanmıştır $F=0,977 ; p=0,325$ ). Benzer şekilde bireysel yenilikçi davranışların çalışma arkadaşları ile çatışma üzerindeki etkisini ölçmek için yapılan regresyon analizi sonucu da istatistiksel olarak anlamlı bulunmamıştı $(\Delta \mathrm{F}=1,447 ; \mathrm{p}=0,231)$. Araştırmanın üçüncü hipotezinin test edilmesi maksadıyla çalışma arkadaşları ile çatş̧ma ve iş ten ayrılma niyeti arasındaki etkileşimi belirlemek için yapılan regresyon analizi sonucu da istatistiksel olarak anlamlı bir sonuç vermemiştir $(F=0,168 ; p=0,683)$. Bu doğrultuda araştırmanın üç hipotezi de desteklenmemektedir.

Araştırmada literatürle örtüşmeyen sonuçlara ulaşılmış ve savunma sanayinde çalışanların bireylerin yenilikçi davranışlarının çalışma arkadaşları ile çatışma düzeyleri ve işten ayrılma niyetleri üzerinde anlamlı bir etkisi olmadığı tespit edilmiştir. Bu sonucun, yüksek teknolojinin kullanıldığı, uzman personel istihdamı gerektiren, rekabet avantajının sürdürülebilmesi için çalışanların yenilikçi inisiyatifler sergilemesinin beklendiği Savunma Sanayi kuruluşlarının (Şeşen, 2010: 171), sektörde etkili olabilmek için büyük ölçüde yenilikçi, risk alabilen ve proje gruplarında başarılı olabilecek çalışanları istihdam ettiğinden kaynaklanabileceği düşünülmektedir. Ancak araştırma sonucunun yapısal ve örgütsel bağlamda nedenleri olabileceği düşüncesinden hareketle, nitel bir araştırma yöntemi olan odak grup çalışmasının yapılmasının yararlı olacağı düşünülmüştür. Nitekim odak grup çalışmaları anlamayı, nedenleri tanımlamayı ve katılımcıların durumu nasıl algıladıklarını ortaya çıkarmayı amaçlayan bir nitel araştırma yöntemidir (Krueger, 1994). Daha çok yüzeysel bilgilerin edinilmesi hedeflenen odak grup çalışmalarında, katılımcıların farklı görüş 
açılarının değerlendirilmesi Araştırmanın yapıldığı kamu kuruluşundan beş çalışanın katılımıyla bir buçuk saat süreli bir odak grup çalışması yapılmış ve sonuçları aşağıda tartışımıştır.

\subsection{Nitel Araştirma}

Araştırmanın ikinci aşaması olarak yapılan odak grup toplantısına araştırmacılardan birisi kolaylaştırıcı olarak katılmıştır. Odak grup toplantlları fikir üretilmesi için kullanılabilecek yöntemlerden birisidir (Kitzinger, 1994: 108). Odak grup toplantıları kısa sürede birden fazla kişiyle görüşmeyi sağladığı gibi farklı bakış açılarını duymak ve onların karşılıklı görüşmesini temin etmek için bir zemin de hazırlamaktadır (Beyea ve Nicholl. 2000).

Odak grup toplantısındaki kişi sayısı araştırmanın amacına uygun şekilde belirlenmektedir (Krueger ve Casey, 2000). Odak grup toplantılarında evreni temsil özelliğinden ziyade farklı perspektifi verecek kişilerin bulundurulması daha ön plandadır (Kitzinger, 1994). Odak grubun büyüklüğü 6-8 kişi olarak tavsiye edilmekle birlikte 3-12 arası kişiden de oluşturulabileceği belirtilmektedir (Krueger ve Casey. 2000; Lane vd., 2001). Bu çerçevede, odak grup toplantısı beş kişi ile sınırlı tutulmuş, katlımcıların farklı birimlerden olmasına özen gösterilmiştir. Odak grup toplantısına katılım sağlayanlara ilişkin bilgiler Tablo 5'de gösterilmektedir.

Tablo 5. Odak Grup Katılımcı Bilgileri

\begin{tabular}{|l|c|c|}
\hline & Orta Kademe Yönetici & Çalışan \\
\hline Statü & 1 & 4 \\
\hline & Lisans & Lisansüstü \\
\hline Eğitim Durumu & 4 & 1 \\
\hline & Erkek & Kadın \\
\hline Cinsiyet & 2 & 3 \\
\hline Yaş Ortalaması & \multicolumn{2}{|c|}{31} \\
\hline Deneyim & 6 yıl \\
\hline
\end{tabular}

Ana hizmet birimlerinin yanı sıra insan kaynakları biriminden de katılım sağlanmıştır. Odak gruba katlanların birisi orta kademe yönetici, diğerleri birim uzmanlarıdır. Yaş ortalaması 31 olan katılımcıların mesleki deneyimleri ortalama 6 yıldır. Birisinin yüksek lisans, diğerlerinin lisans derecesine sahip olduğu katlımcılardan ikisi kadın, üçü erkektir.

Odak grup toplantısı kurumun hizmet binasında yapılmış ve kurumsal aidiyet konusuna özen gösterilmiştir. Aynı zamanda araştırmacının kurumda gözlem yapmasına firsat yaratılmıştır. Odak grupların temel özelliği kolaylaştırıının eşliğinde yapılması, ancak kolaylaştırıcının özellikle erken aşamalarda mümkün olduğu kadar tartışmaya müdahaleden kaçınmasıdır (Kitzinger, 1994: 106). Ayrıca kolaylaştırıcı katılımcıların rahat bir şekilde fikrini ifade edebilmesi için farklı aktiviteler yaptrabilmeli ve yenilikçi yöntemler kullanabilmelidir.

Odak grup ile nicel araştırma sonuçları paylaşıımış ve toplantının amacının "literatürden farklı elde edilen bulgulara tesir eden faktörlerin belirlenmesi" olduğu açıklanmıştır. Odak grup çalışmalarında sınırlı sayıda kavramın tartışılmasına önem verildiği için (Edmunds, 2000) odak gruba yedi soru yöneltilmiş ve araştırmacının kolaylaştırıcılığında soruları sıra ile tartş̧maları istenmiştir. Nitel verilerin yorumlanmasında, derlenmesinde ve açıklanmasında kodlamalar sıklıkla kullanılmaktadır. Bu çalışmada yapılan odak grup toplantısında sorulara verilen cevaplar neticesinde Tablo 6' da görüldüğü üzere kullanılan kodlamalar ve frekanslar elde edilmiştir.

Tablonun incelenmesinde en fazla tekrar eden kelimenin "mutluyum" ifadesi olduğu görülmektedir. Daha sonra frekansı iki olan "yeniliğe açık", "farklılı", "özlük hakları", "kişiselleştirmeme", "çalışma birimini belirleme" ve "uzun vadeli projeler" gelmektedir. Buradan hareketle örgüt kültürünün yenilikçilik temelinde kurgulandığı, farklılıklara müsaade edildiği, uzun vadeli projelerde çalışıldığı, liderin etkili olduğu çıkarımında bulunmak mümkündür. Değerlendirmeleri anlamak için soru bazlı inceleme de yapılmıştr. 
A. Eroglu-M. K. Topcu-H. N. Basim

Tablo 6. Kodlamalar ve Frekanslar

\begin{tabular}{|l|l|l|l|l|l|}
\hline S.Nu. & \multicolumn{1}{|c|}{ Kodlama } & $\mathrm{f}$ & S.Nu. & \multicolumn{1}{|c|}{ Kodlama } & $\mathrm{f}$ \\
\hline 1 & Dinamik bir kurum & 1 & 20 & Bilinçli kullanım & 1 \\
\hline 2 & Kaliteli iş & 1 & 21 & Yerinde kullanım & 1 \\
\hline 3 & Yeniliğe açık & 2 & 22 & Çalışma birimini belirleme & 2 \\
\hline 4 & Genç kurum & 1 & 23 & Terfide etkili & 2 \\
\hline 5 & İşin önemi & 1 & 24 & Yüksek bütçeli projeler & 1 \\
\hline 6 & Özlük hakları & 2 & 25 & Uzun vadeli projeler & 2 \\
\hline 7 & Stratejik bakış açısı & 1 & 26 & Stratejik planlama & 1 \\
\hline 8 & Gelişimi teşvik & 1 & 27 & Ekip çalışması & 1 \\
\hline 9 & Mutluyum & 3 & 28 & Paydaşlarla işbirliği & 1 \\
\hline 10 & Huzurlu & 1 & 29 & Farklılık & 2 \\
\hline 11 & Ortak çalışma & 1 & 30 & Önyargısız & 1 \\
\hline 12 & Samimiyet & 1 & 31 & Gelişimi teşvik & 1 \\
\hline 13 & Kişiselleştirmeme & 2 & 32 & Uzlaşma & 1 \\
\hline 14 & Sabır & 1 & 33 & İnsan faktörü & 1 \\
\hline 15 & Özür dilemek & 1 & 34 & Çatışma yönetimi & 1 \\
\hline 16 & İyi niyet & 1 & 35 & ilişkilerde temel belirleyici & 1 \\
\hline 17 & Tarz farklılığı & 1 & & & \\
\hline 18 & İletişim eksikliği & 1 & & & \\
\hline 19 & Gelişim için kullanmak & 1 & & & \\
\hline
\end{tabular}

"Örgütte uzun dönemli (veya önümüzdeki 2-3 sene) kalmayı düşünüyor musunuz? Kalmanızı teşvik eden sebepler neler olabilir?" sorusuna ilişkin katılımcıların birisi hariç diğerleri uzun dönemli örgütte kalmayı düşündüklerini belirtmiştir. İşten ayrılma niyetinde olan katılımcının temel argümanı özlük haklarının iyileştirilmesi gerektiği yönündedir. Diğer yandan örgütte kalma niyetinde olan katılımcıların argümanı ise örgütün stratejik işler yapması ve bireysel gelişimi teşvik etmesi olduğunu belirtmiştir. Örneğin Katlımcı D tarafindan örgüt "...Kurumun gelişimimi teşvik ettiğini düşünüyorum. Yeni şeyler öğrenmek ve iş ortamı anlamında güzel bir kurum." şeklinde tarif edilmiştir. Kathlımcı $C$ tarafindan desteklenen bu görüş "...Ayrıca yapılan işin ülkemiz açısından önemli ve kritik olduğuna inanıyorum, bu yüzden konumumu önemsiyorum." şeklinde genişletilmiştir. Nitekim Katılımcı A da "...aynı kurumda yetki alanı daha geniş bir pozisyonda uzun yıllar hizmet vermek isterim." ifadesiyle kariyer olanaklarını ön plana çıkarmıştır.

"işse gelirken iyi duygular besliyor musunuz? İşyerinde mutlu musunuz?" sorusuna cevaben katılımcıların birisi hariç diğerleri mutlu olduklarını belirtmiş ve çalışma ortamlarının huzurlu olduğunu ifade etmiştir. Kathlımcı E ise "bazen" iyi duygular beslediğini ve "bazen" mutlu olduğunu belirtmiştir.

"Çalışma arkadaşları ile çatışma yaşar mısınız? Hangi nedenlerden ötürü çatışırsınız? Çatışma yaşamıyorsunuz nedenleri nelerdir?" sorusuna katlımcılar çalışma arkadaşları ile çok sık çatışma yaşamadıkları cevabını vermiştir. Çatışma yaşama nedenleri arasında kişilik, görüş ayrılıkları, tarz farklıığı ve iletişim noksanlığı ön plana çıkmıştır. Çatışma yaşanmaması nedenleri arasında ise ortak çalışma, kişiselleştirmeme, samimi ilişkiler kurma, iş odaklılık ve iyi niyet olarak sıralanmıştır. Kişiliğin çatş̧madan kaçınmadaki rolü açısından Katılımcı C'nin "Genelde sabırlı davranıyorum ve gerektiğinde özür dilemekten çekinmiyorum." ifadesi ilgi çekici olmuştur. Ayrıca Katılımcı D “... çatışmaları ... gelişim için kullanabilmek önemli." açıklamasında bulunarak farklı bir bakış açısı getirmiştir.

"Amirlerin yetki alanını (veya yaptırım gücünü) etkili görüyor musunuz? Açıklayınız." Sorusu tartışıırken, katılımcılardan A ve $E$ yöneticilerin daha etkili olabileceğini vurgularken, diğer katılımcılar yöneticilerin terfi, kariyer ve performans yönünden yetkilerine atfta bulunmuştur. Örneğin Katılımcı B "Amirlerin sicil notu verme, terfi ya da istediğiniz birimlerde çalışmanızda etkisi önemlidir." belirterek liderlik becerilerinden ziyade yönetsel becerilere işaret etmiştir.

"Çalıştı̆ı̆ız kurumda işler/projeler nasıl sürdürülmektedir?" sorusuna katılımcılar farklı açılardan yaklaşmakla birlikte genel olarak paydaş yaklaşımına, stratejik yönetime, uzun vadeli planlamaya ve ekip 
çalışmasına değinmiştir. Örneğin Katılımcı D "Farklı paydaşlarla birlikte ve ekip çalışması ile yürütülmektedir." ifadesi ile iç ve dış paydaşlara işaret ederken, Katılımcı A "Yüksek bütçeli ve uzun yıllara yayılmış olan projeler..." ifadesi ile uzun vadeli planlama ve stratejik yönetime atıla örgütsel faaliyetlerin stratejik önemine değinmiştir.

"Sizce çalışma arkadaşları ile yaşanan çatışmanın derecesi optimal olabilir mi? Bu yenilikçiliği yaşatır mı? Başka nedenleri ya da sonuçları olabilir mi?" sorusu yöneltildiğinde katlımcılar iş ortamında çatı̧manın optimal bir derecede sağlıkı olacağı konusunda hemfikirdir. Ancak katılımcıların bazı ön koşullar öne sürdüğü görülmüştür. Örneğin Katılımcı A "gereksiz inat ve ısrarcılık", Katılımcı C "kişiselleştirme ve ön yargı" olmadan çatışmanın yaşanması gerektiğini belirtmiştir. Katılımcılar çatş̧maların yenilikçiliği olumlu etkilediğini düşünmektedir. Aykırı olarak Katılımcı B "Yenilikçilik için çatışmadan çok uzlaşma önemlidir." görüşünü ifade etmiştir.

"Sizce aynı durumun başka bir kamu kurumunda yaşanma olasılığı var mıdır? Tartışınız." sorusuna cevaben katılımcılar çatı̧̧maların her örgütte yaşanabileceğini belirtmiştir. Katılımcı A bu durumu "insan" faktörüne bağlamıştır. Katılımcı B de çatş̧mayı “...evlilik kurumunda bile ilişkileri belirleyen temel parametredir." şeklinde niteleyerek Katılımcı A'yı desteklemiştir. Diğer taraftan Katılımcı C çatışma yönetimine değinerek "...sosyo ekonomik ve sosyo kültürel gelişmişlik düzeyi arttıkça, çatı̧maların daha profesyonel yönetildiğini..." belirtmiştir.

\section{Sonuç}

Örgütsel etkililiği sürdürmek ve geliştirmek için bireylerin yenilikçi davranışlar sergilemesine her zaman ihtiyaç olmasına rağmen (Ancona ve Caldwell, 1987: 1; Janssen vd., 2004: 129; Oldham ve Cummings, 1996: 607; Scott ve Bruce, 1994: 580; Shih ve Susanto, 2011: 111; Yuan ve Woodman, 2010: 323; Montani vd., 2012: 46), alışılmıs uygulamaların dışında yenilikçi yaklaşımlar sergileyen çalışanlar, kuruma olumlu katkıları karşıllı̆ında bir bedel ödemek zorunda kalabilmektedir (Janssen, 2003: 357).

Mintzberg (1979)'e göre kamu sektöründe yer alan örgütler profesyonel bürokratik bir yapı içerisinde fonksiyonlarını sürdürmektedir. Böyle bir bürokratik bağlamda, yenilikçiliğin görece tipik olmayan doğası nedeniyle çalışanların yenilikçi yaklaşımlar sergilemesi çatışmayı tetikleyebilir. Bu nedenle yenilikçi davranışın karanlık yönünü ortaya çıkarmak maksadıyla araştırmanın örneklemi olarak; yenilikçi inisiyatiflerin örgüt performansını artırmak için (Ancona ve Caldwell, 1987: 1; Oldham ve Cummings, 1996: 607; Turunç vd., 2013: 603) özellikle teşvik edildiği özel sektörden ziyade sergilediği performansa bakılmaksızın her durumda ücretlerin ödenebildiği, işgücü devrinin çok düşük düzeylerde olduğu ve özellikle "bir fikrim var" diyene "eski köye yeni adet getirme" şeklinde yaklaşımların sergilenebildiği kamu sektörü seçilmiştir.

Örgüt normları paralelinde hareket eden çalışanlar, yeni görev tanımları, yeni iş ilişkileri ve yeni grup normları anlamına gelen yenilikçi yaklaşımlara (Jones, 2001), beraberinde güvensizlik, belirsizlik ve stres getirebileceğinden ötürü direnç göstermeye eğilim göstermektedir (Argyris, 1957; Jones, 2001; Lewin, 1951; Likert, 1967). Ayrıca çalışma arkadaşlarının, Lewin (1951) tarafindan geliştirilen "Değişime Direnç" literatürü temelinde, yenilikçi yaklaşımların yaratacağı değişimin etrafindaki stres ve güvensizlikten kaçınma arzuları, alışkanlıkları ve aşina oldukları uygulama öncelikleri, bilişsel uyumsuzluğu azaltma istekleri ve mevcut nazariye ile uygulamalara bağlılıkları yüzünden değişime dönük yenilikçi fikirleri engelleyici tutum içerisinde olabilecekleri söylenebilir (Janssen, 2003: 349). Bu kuramsal gerçekliğin aksine, savunma sanayinde çalışanların katıldığı bu araştırmanın bulguları, bireylerin yenilikçi davranış algılamaları ile çalışma arkadaşları ile çatışma düzeyleri ve işten ayrılma eğilimleri arasında anlamlı bir ilişki olmadığına işaret etmektedir.

Bu bulgu, Janssen (2003: 354)ın 76 ortaokul öğretmeni üzerinde yaptı̆̆ı araştırmadaki, bireylerin yenilikçi davranışları ve çalışma arkadaşları ile çatışma arasında pozitif bir ilişki olduğu sonucu, Shih ve Susanto (2011: 111)nun üretim ve pazarlama sektöründe çalışan 135 yönetici ile işgören üzerinde yapthğı araştırmadaki, bireylerin yenilikçi davranışları ile çalışma arkadaşlarıyla çatışma ve işten ayrılma niyeti arasında anlamlı ve pozitif bir ilişki olduğu sonucu veya Sönmez ve Yıldırım (2014: 54) tarafindan yenilikçiliğin fikirden uygulamaya dönüşebilmesi çalışma arkadaşları tarafindan saygıyla ve hoşgörüyle karşılanması gerektiği ve yenilikçi fikre sahip çalışanların çatışmadan kaçınmak için fikirlerinden vazgeçtikleri yönündeki tespitler ile örtüşmemektedir. 
Bu sonucun, yüksek teknolojinin kullanıldığı, uzman personel istihdamı gerektiren, rekabet avantajının sürdürülebilmesi için çalışanların yenilikçi inisiyatifler sergilemesinin beklendiği savunma sanayi kuruluşlarının (Şeşen, 2010: 171), sektörde etkili olabilmek için büyük ölçüde yenilikçi, risk alabilen ve proje gruplarında başarılı olabilecek çalışanları istihdam ettiğinden kaynaklanabileceği düşünülmektedir.

Ancak araştırma sonucunun yapısal ve örgütsel bağlamda nedenleri olabileceği düşüncesinden hareketle, araştırmacılar tarafindan nitel bir çalışma daha yapılmıştır. Odak grup çalışması ile yapılan nitel araştırma sonuçlarına göre çatışmanın yenilikçiliği tetiklediği yönünde ağır basan bir görüş olmuştur. İnsanın olduğu her yerde kaçınılmaz bir şekilde çatışmalar yaşanacaktır. Ancak bu çatışmaların bireylerin, örgütlerin ve toplumun menfaatine yönlendirilmesi önem taşımaktadır. Araştırma yapılan örgütün bir kamu kurumu olması bir kısıtılık gibi dururken, sektör olarak savunma sanayi olması bu kısıtlılıgı ortadan kaldırmaktadır. Ancak liderlik özelliklerinden ziyade yönetsel becerilerin devrede olduğunu belirtmek mümkündür. Zaten liderden kaynaklanan etkilerin varlığına rağmen çalışanların algılarının, tutumlarının, geri çekilme davranışlarının ve etkililiklerinin akranlardan etkilenme olasılığı daha yüksektir (Chiaburu ve Harrison, 2008: 1084). Ancak araştırma yapılan örgüt bağlamında akranlardan kaynaklanan çatışmaların makul bir seviyede olduğu anlaşılmaktadır. Olumsuz bir anlam barındırmakla birlikte çalışma arkadaşları ile çatışma yaratıcılığın ve yenilikçiliğin de kaynağı olabilmektedir (Basım vd., 2009: 21). Amabile vd. (1996) bireysel yenilikçi davranışların yapılan işin niteliğine göre farklılaştığını belirtmektedir. Nitel araştırmaya katılan uzmanlar da çatışmaları kişiselleştirmeden, iş odaklı yaklaştıklarını, çatşmaları gelişim için kullanılabilecek firsatlar olarak gördüklerini belirtmiştir. Zira örgüt genel olarak bireysel gelişim için olanak sunmakta, kariyer gelişimi sağlamaktadır. Ayrıca, odak grupta yer alan uzmanların ifadeleri mesleki ve örgütsel bağlılığın olduğuna işaret etmektedir. Ayrıca çalışanların stratejik ve önemli işler yaptıklarına olan inançları aidiyet duygusunu daha da pekiştirmektedir. Doğal bir sonuç olarak da örgütte kalma niyeti daha fazla ön plana çıkmaktadır.

Buradan hareketle örgüt bağlamında pozitif bir çalışma ortamının hâkim olduğu kanaatine varılabilir. Sönmez ve Yıldırım (2014: 54) tarafindan yapılan nitel araştırma sonucunda yenilikçiliği etkileyen örgütsel faktörler arasında pozitif çalışma ortamı da yer almaktadır. Amabile vd. (1996) de bireysel yenilikçi davranışların ortaya çıkması için pozitif çalışma ortamı yaratılması, kaynak sağlanması ve yönetim tarafindan serbestlik ve yetki tanınmasının gerekli olduğunu vurgulamaktadır. Çalışma ortamında huzur var ise, çalışanlar birbirlerine destek oluyorsa, çalışanların iş tatmin seviyelerinin daha yüksek olduğu görülmektedir (Pollock, Whitbred ve Contractor, 2000). Çalışma arkadaşları arasındaki iyi ilişkiler çalışanların işlerine bağlanma derecesini de olumlu etkilemektedir (Nugent ve Abolafia, 2006). Çalışma arkadaşlarından destek görülmesi çalışanların iş performanslarını da olumlu etkilemektedir (Ensher, Thomas ve Murphy, 2001; Harrison et al., 2006). Çalışma arkadaşları akranlarına mentoring yaparak, görevlerin önceliklendirilmesine ilişkin ipucu vererek çatı̧̧maların azalmasına yardımcı olabilmektedir (Chiaburu ve Harrison, 2008). Çalışma arkadaşlarından yardım ve destek gören çalışanların devamsızlıklarında düşüş de gözlenmiştir (Iverson, Olekalns ve Erwin, 1998).

Burada örgütsel kültürle birlikte insan kaynakları uygulamalarının rolü daha net ortaya çıkmaktadır. Pozitif bir çalışma ortamı; işe ve örgüte uyum sağlayacak kişilerin işe alınması, kişilerin uygun işe yerleştirilmesi, iş tasarımlarının yapılarak özellikle rotasyon, derinleştirme ve zenginleştirmelere gidilmesi, eğitimlerle birlikte geliştirmenin üzerinde durulmasını gerektirmektedir. İnsan kaynakları uygulamalarının inovasyon ile ilişkilendirilmesi örgütsel kültürün bir parçası haline getirilebilirse pozitif çalışma ortamının yanı sıra yenilikçi bir iklim de yaratılmış olacaktır. Yönetimin paylaşımcılığı ve katılımcılığı teşvik etmesi bireysel yenilikçi davranışların ortaya çıkmasında önemli ve etken örgütsel faktörlerden birisidir (Sönmez ve Yıldırım, 2014: 54). Çatı̧̧maların yenilikçi fikirleri tetiklediği de yadsınamaz bir gerçektir. Çatışmalardan kaçınmak yerine farklılıkların yönetilmesine yönelmek örgütleri geleceğe taşımanın bir parçası, bir başlangıcı olabilir. Ancak bu alanda çalışmalar yok denecek kadar azdır. Araştırmacılar tarafindan yapılacak farklılıkların yönetilmesi, çatş̧ma, yenilikçilik, kültür ve strateji konularını içeren çalışmalar sahadaki uzmanlara da ışık tutacaktr.

Mevcut çalışmada elde edilen bulgular yorumlanırken, uygulama düzeyinde bazı kısıtları göz önünde bulundurmak gerekmektedir. Öncelikle, araştrrma sonucu elde edilen bulgular, verilerin toplanmasında kullanılan örnekleme göre değişiklik gösterebileceğinden araştırmanın bulguları, verilerin toplandığı örneklem ile sınırlıdır. İkinci olarak; araştırmada kullanılan ölçekler bireylerin tutumlarını ve algılamalarını 
değerlendirmektedir. Bu nedenle ortak yöntem varyansı ve sosyal beğenirlik etkisi gibi kısıtların bulguların yorumlanmasında dikkate alınması gerektiği düşünülmektedir. Üçüncü kısıt ise örneklemin kendisi ile ilgilidir. Çalışmanın örneklemi, savunma sanayi sektöründe Ankara'da faaliyet gösteren bir kamu örgütünü kapsadığı için genelleme yapılırken dikkat edilmesi gerekmektedir. Nitekim örneklemin genişletilmesi ve özel sektörü de kapsayacak şekilde farklılaştırılması halinde daha genellenebilir sonuçlara ulaşılabileceği değerlendirilmektedir.

\section{Kaynaklar}

Abassi, S. M., \& Hollman, K.W. (2000). Turnover: The real bottom line. Public Personnel Management, 2(3),333-342.

Amabile, T. M., Conti, R., Coon, H., Lazenby, J., \& Herron, M. (1996). Assessing the work environment for creativity. Academy of Management Journal, 39(5), 1154-1184.

Ancona, D., \& Caldwell, D. (1987). Management issues facing new product teams in high technology companies. D. Lewin, D. Lipsky, \& D. Sokel (Eds.), Advances in Industrial and Labor Relations (Vol. 4, 191-221). Greenwich, CT: JAI.

Argyris, C. (1957). Personality and Organization. New York: Harper \& Row.

Arnold, H. J., \& Feldman, D. C. (1982). A multivariate analysis of the determinants of job turnover. Journal of Applied Psychology, 67(3), 350-360.

Basım, H. N., Korkmazyürek, H., \& Tokat, A.O. (2008). Çalışanların öz yeterlilik algılamasının yenilikçi ve risk alma üzerine etkisi: Kamu sektöründe bir uygulama. Sosyal Bilimler Dergisi, 19, 121-130.

Basım, H. N., Çetin, F., \& Tabak, A. (2009). Beş faktör kişilik özelliklerinin kişilerarası çatı̧̧ma çözme yaklaşımlarıyla ilişkisi. Türk Psikoloji Dergisi, 24(63), 20-34.

Bentler, P. M. (1990). Comparative fit indexes in structural models. Psychological Bulletin, 107(2), 238-246.

Beyea, S. C., \& Nicholl, L. H. (2000) Leam more using focus groups, Association of Operating Room Nurses. AORN Journal, 71(4), 897-900.

Chen, P. Y., \& Spector, P. E. (1992). Relationships of work stressors with aggression, withdrawal, theft, and substance use: An exploratory study. Journal of Occupational and Organizational Psychology, 65, 177-184.

Chiaburu, D. S.i \& Harrison, D. A. (2008). Do peers make the place? Conceptual synthesis and meta-analysis of coworker effects on perceptions, attitudes, OCBs, and performance. Journal of Applied Psychology, Vol. 93, No. 5, 10821103.

Cohen, G., Blake, R. S., \& Goodman, D. (2016). Does turnover intention matter? Evaluating the usefulness of turnover intention rate as a predictor of actual turnover rate. Review of Public Personnel Administration, 36(3), 240-263.

De Dreu, C. K. W., van Dierendonck, D., \& Dijkstra, M. T. M. (2004). Conflict at work and individual well being. International Journal of Conflict Management, 15(1), 6-26.

De Lange, A. H., De Witte, H., \& Notelaers, G. (2008). Should I stay or should I go? Examining longitudinal relations among job resources and work engagement for stayers versus movers. Work \& Stress, 22, 201-223.

Dess, G. D., \& Shaw, J. D. (2001). Voluntary turnover, social capital, and organizational performance. Academy of Management Review, 26(3), 446-56.

Edmunds, H. (2000). The focus group research handbook. Lincolnwood, IL: NTC Publishing Group.

Ensher, E. A., Thomas, C., \& Murphy, S. E. (2001). Comparison of traditional, step-ahead, and peer mentoring on proteges' support, satisfaction, and perceptions of career success: A social exchange perspective. Journal of Business and Psychology, 15, $419-438$.

Frone, M.R. (2000). Interpersonal conflict at work and psychological outcomes: Testing a model among young workers. Journal of Occupational Health Psychology, 5(2), 246-255.

Gouldner, A. W. (1960). The norm of reciprocity: A preliminary statement. American Sociological Review, 161-178.

Halbesleben, J. R., \& Wheeler, A. R. (2008). The relative roles of engagement and embeddedness in predicting job performance and intention to leave. Work \& Stress, 22(3), 242-256.

Harrison, D. A. (2002). Meaning and measurement of work role withdrawal: Current controversies and future fallout under changing technology. M. Koslowsky \& M. Krausz (Eds.), Voluntary Employee Withdrawal and Inattendance: A Current Perspective (pp. 95-132). London: Plenum Publishing. 
Harrison, D. A., Newman, D. A., \& Roth, P. L. (2006). How important are job attitudes? Meta-analytic comparisons of integrative behavioral outcomes and time sequences. Academy of Management Journal, 49, 305-325.

Hobfoll, S.E. (1998). Stress, Culture, and community: The psychology and physiology of stress. New York: Plenum Press.

Hu, L., \& Bentler, P. M. (1999). Cutoff criteria for fit Indexes in covariance structure analysis: Conventional criteria versus new alternatives. Structural Equation Modeling, 6(1), 1-55.

Iverson, R. D., Olekalns, M., \& Erwin, P. J. (1998). Affectivity, organizational stressors, and absenteeism: A causal model of burnout and its consequences. Journal of Vocational Behavior, 52, 1-23.

Jam, F. A., Ul Haq, I., \& Fatima, T. (2012). Phychological contract and job outcomes: Mediating role of affective commitment. Journal of Educational and Social Research, 2(4), 79-90.

Janssen, O. (2000). Job demands, perceptions of effort-reward fairness and innovative work behaviour. Journal of Occupational and Organizational Psychology, 73, 287-302.

Janssen, O. (2003). Innovative Behavior and job involvement at the price of conflict and less satisfactory relations with co-workers. Journal of Occupational and Organizational Psychology, 76, 347-364.

Janssen, O., Van De Vliert, E., \& West, M. (2004). The bright and dark sides of individual and group innovation: A special Issue introduction. Journal of Organizational Behavior, 25, 129-145.

Jones, G. R., (2001). Organizational theory: Text and cases. New York: Addison-Wesley.

Kanter, R. (1988). When a thousand flowers bloom: structural, collective, and social conditions for innovation in organizations. B. M. Staw, \& L. L. Cummings [Eds.). Research in Organizational Behavior (Vol. 10, pp. 169-211). Greenwich. CT: JAI Press.

Kidwell, R. E., Jr., \& Bennett, N. (1993). Employee propensity to withhold effort: A conceptual model to intersect three avenues of research. Academy of Management Review, 18, $429-456$.

Kitzinger, J. (1994). The methodology of focus groups: the importance of interaction between research participants. Sociology Of Health \& Illness, 16(1), 103-121.

Kline, R. B. (2004). Beyond significance testing: Reforming data analysis methods in behavioral research. USA: American Psychological Association.

Krueger, R. A. (1994). Focus groups. A practical guide for applied research (2nd Edition). London: Sage Public

Krueger, R. A., \& Casey, M.A. (2000) Focus groups: A practical guide for applied research. Newbury Park: Sage.

Lane, R., McKenna, H., Ryan, A. A., \& Fleming, P. (2001). Focus group methodology. Nursing Research, 8(3): 45-59

Lewin, K. (1951). Field theory in social science. New York: Harper and Row.

Likert, R. (1967). The human organization. New York: McGraw-Hill.

Mafini, C., \& Dubihlela, J. (2013). Determinants of military turnover of technical Air-force specialists: An empirical case analysis. Mediterranean Journal of Social Sciences, 4(3), 523-534.

Marsh, H. W., Balla, J. R., \& McDonald, R. P. (1988). Goodness-of-fit indexes in confirmatory factor analysis: The effect of sample size. Psychological Bulletin, 103(3), 391-410.

Martin, T. N., Price, J. L., \& Mueller, C. W. (1981). Job performance and turnover. Journal of Applied Psychology, 66(1), 116-119.

Mathieu, J. E., \& Kohler, S. S. (1990). A cross-level examination of group absence influences on individual absence. Journal of Applied Psychology, 75, 217-220.

Mimaroğlu, H. (2008). Psikolojik sözleşmenin personelin tutum ve davranışlarına etkileri: Tıbbi satış temsilcileri üzerinde bir araştırma. Çukurova Üniversitesi Sosyal Bilimler Enstitüsü, Yayımlanmamış Doktora Tezi, Adana.

Mintzberg. H. (1979). The structuring of organizations. Englewood Cliffs, NJ: Prentice Hall.

Montani, F., Odoardi, C., \& Battistelli, A. (2012). Explaining the relationships among supervisor support, affective commitment to change, and innovative work behavior: The moderating role of coworker support. Bolletino Di Psicologia Applicata, 264, 43-57.

Nugent, P. D., \& Abolafia, M. Y. (2006). The creation of trust through interaction and exchange: The role of consideration in organizations. Group \& Organization Management, 31, 628 - 650.

Oldham, C. R., \& Cummings, A. (1996). Employee creativity: Personal and contextual factors at work. Academy of Management Journal, 39, 607-634. 
Pollock, T. G., Whitbred, R. C., \& Contractor, N. (2000). Social information processing and job characteristics: A simultaneous test of two theories with implications for job satisfaction. Human Communication Research, 26, 292-330.

Porter, L. W., \& Steers, R. M. (1973). Organizational, work, and personal factors in employee turnover and absenteeism. Psychological Bulletin, 80(2), 151-176.

Rainey, D. W. (1995). Sources of stress among baseball and softball umpires. Journal of Applied Sport Psychology, 7, 110.

Schwartz, J. E., \& Stone, A. A. (1993). Coping with daily work problems: contribution of problem content, appraisals, and person factors. Work \& Stress, 7(1), 4762.

Scott, S. G., \& Bruce, R.A. (1994). Determinants of innovative behavior: A path model of individual innovation in the workplace. Academy of Management Journal, 37, 580-607.

Shih, H., \& Susanto, E. (2011). Is innovative behavior really good for the firm? Innovative work behavior, conflict with coworkers and turnover intention: Moderating roles of perceived distributive fairness. International Journal of Conflict Management, 22(2), 111-130.

Sonnentag, S., Unger, D., \& Nägel, I. J. (2013). Workplace conflict and employee well-being: The moderating role of detachment from work during off-job time. International Journal of Conflict Management, 24(2), 166-183.

Sönmez, B., \& Yıldırım, A. (2014). Bir üniversite hastanesinde çalışan hemşirelerin yenilikçi davranışları ve yenilikçi davranışlarını etkileyen faktörlere ilişkin görüşlerinin belirlenmesi: Niteliksel bir çalışma. Sağlık ve Hemşirelik Yönetimi Dergisi, 1(2), 49-59.

Spector, P. E. (1998). A control theory of the job stress process. C. L. Cooper (Ed.), Theories of organizational stress (pp. 153-169). Oxford, UK: Oxford University Press.

Spector, P. E., \& Bruk Lee, V. (2008). Conflict, health, and well being. C.K.W. De Dreu \& M. J. Gelfand (Eds.), The Psychology of Conflict and Conflict Management in Organizations (pp. 267-288), New York: Lawrence Erlbaum Associates.

Spector, P. E., \& Jex, S. M. (1998). Development of four self-report measures of job stressors and strain: Interpersonal conflict at work scale, organizational constraint scale, quantitative workload inventory, and physical symptoms inventory. Journal of Occupational Health Psychology, 3, 356-367.

Şeşen, H. (2010). Öncülleri ve sonuçları ile örgüt içi girişimcilik: Türk savunma sanayinde bir araştırma. Kara Harp Okulu Savunma Bilimleri Enstitüsü, Yayımlanmamış Doktora Tezi, Ankara.

Tabachnick B. G, \& Fidell L. S. (2001). Using multivariate statistics. Boston: Allyn and Bacon.

Tak, B., \& Çiftçioğlu, A. (2009). Algılanan örgütsel prestij ile örgütsel bağlılık ve örgütsel özdeşleşme arasındaki ilişkilerin incelenmesine yönelik bir araştırma. Akdeniz Üniversitesi Iktisadi ve Idari Bilimler Fakültesi Dergisi, 18, 100-116.

Tett, R. P., \& Meyer, J.P. (1993). Job satisfaction, organizational commitment, turnover intention, and turnover: Path analyses based on meta analytic findings. Personnel Psychology, 46(2), 259-93.

Topcu, M. K., Gursoy, A., \& Gurson, P. (2015). The Role of the Servant Leadership on the Relation between Ethical Climate Perception and Innovative Work. European Research Studies, 18(1), 67-80.

Turunç, Ö., Türköz, T., Akkoç, İ., \& Çalışkan, A. (2013). How do innovative and entrepreneurial behaviours affect the job performance?: The moderating role of person-organisation fit. International Journal Business Innovation and Research, 7(5), 590-618.

Van de Ven, A. (1986). Central problems in the management of innovation. Management Science, 32, 590-607.

Van de Ven, C. P. H. W. (2001). The drop-out rate during training in line with expectations. In First International Applied Military Psychology Symposium Workshop, held in the Hague, The Netherlands.

Vandenberg, R. J., \& Nelson, J. B. (1999). Disaggregating the motives underlying turnover intentions: When do intentions predict turnover intention. Human Relations, 52(10), 1313-36.

Wall, J. A., \& Callister, R. R. (1995). Conflict and its management. Journal of Management, 21(3), 515-558.

Woodman, R. W., Sawyer, J. E., \& Griffin, R.W. (1993). Toward a theory of organizational creativity. Academy of Management Review, 18, 293-321.

Yu, C., Yu T. F., \& Yu, C. C. (2013). Knowledge sharing, organizational climate and ınnovative behavior: A cross-level analysis of effects. Social Behavior and Personality, 41(1), 143-156.

Yuan, F., \& Woodman, R. W. (2010). Innovative behavior in the workplace: The role of performance and image outcome expectations. Academy of Management Journal, 53(2), 323-342. 